\title{
PENGEMBANGAN DAN PENERAPAN REKAM MEDIS ELEKTRONIK (RME) DALAM MEMANTAU INSIDEN HIPERTENSI: TELAAH JURNAL
}

\author{
Santi Apriyani ${ }^{1 *}$, Tuti Herawati ${ }^{2}$ \\ 1. Magister Ilmu Keperawatan Universitas Indonesia, Depok-Indonesia \\ 2. Fakultas Ilmu Keperawatan Universitas Indonesia, Depok-Indonesia
}

*Korespondensi: Santi Apriyani | Universitas Indonesia |nadirakayyisah@gmail.com

\begin{abstract}
Abstrak
Pendahuluan: Rekam Medis Elektronik (RME) mulai diterapkan di pelayanan kesehatan untuk mendeteksi dan memonitoring suatu penyakit dan perlu dikembangkan secara luas. Peningkatan kualitas kesehatan menjadi outcome dari pelayanan kesehatan. Penelitian ini bertujuan untuk Memberikan gambaran hasil telaah jurnal tentang pengembangan penerapan Rekam Medis Elektronik (RME) untuk memantau insiden Hipertensi.

Metode: Penelitian ini menggunakan metode telaah jurnal dari online database : J-Stors, Science Direct, Clinical Key dan Pro-Quest dengan kata kunci Nursing Informatics, Electronic Health Record, Hypertension, Monitoring Hypertension, Monitoring Blood Pressure

Hasil: Dari hasil telaah 10 jurnal pilihan, disimpulkan bahwa pemanfaatan RME bisa digunakan secara luas diantaranya memonitoring penyakit hipertensi atau mendeteksi penyakit akibat hipertensi. Penggunaan fitur algoritma secara otomatis, penggunaan anotasi dan monitoring yang terhubung dengan tempat tinggal pasien adalah bagian dari pengembangan dan pemanfaatan system RME.

Kesimpulan: Pemanfaatan RME bisa digunakan untuk memonitoring penyakit hipertensi, mendeteksi penyakit akibat hipertensi dan mencegah kejadian rehospitalisasi.

Kata Kunci: Informatika Keperawatan, Rekam Medis Elektonik, Hipertensi, Pemantauan Hipertensi, Pemantauan tekanan darah.
\end{abstract}

Diterima 14 Agustus 2020; Accepted 30 Desember 2020

\section{PENDAHULUAN}

Pada zaman 4.0 saat ini, teknologi digital dan informasi berkembang sangat pesat. Perkembangan teknologi digital dan informasi sudah merambah kesemua aspek kehidupan. Aspek yang terpengaruh perkembangan tekonogi digital dan informasi yaitu social, ekonomi serta kesehatan. Perkembangan teknologi dalam aspek kesehatan memberi dampak yang positif untuk pelayanan kesehatan dan informasi kesehatan. Salah satu perkembangan teknologi digital dan informasi di bidang pelayanan kesehatan yaitu adanya Electronic medical record (EMR) atau Rekam medis elektronik (RHE). Electronic Medical Record $(E M R)$ atau Rekam Medis Elektronis (RME) adalah rekam medis yang sudah terkomputerisasi yang berisi data demografi, catatan klinis, dan manajemen informasi di pelayanan kesehatan khususnya rumah sakit (Özer \& Şantaş, 2020). RME ini berfungsi untuk menyimpan, mengelola, mentransmisi data yang berasal dari alat elektronik yang digunakan untuk mengganti rekam medis konvensional. RME dapat berkembang luas tidak hanya digunakan di RS akan tetapi bisa diaplikasikan di rumah dan bisa diakses oleh keluarga atau petugas kesehatan. RME berisi dua informasi utama yaitu deskripsi tekstual dan indicator fisik dari status pasien.

Hipertensi merupakan faktor pemicu Penyakit Tidak Menular seperti penyakit jantung dan stroke. Menurut data Riskesdas tahun 2018 (Kemenkes, 2018) Hipertensi memiliki prevalensi yang tinggi di Indonesia, yaitu sebesar $34.1 \%$. Hipertensi adalah tekanan darah sistolik $\geq 140 \mathrm{mmHg}$ dan tekanan darah diastolik $\geq 90 \mathrm{mmHg}$ (Chen et al., 2020). Hipertensi yang tidak terkontrol dapat menurunkan kualitas hidup pasien dan meningkatkan kejadian rehospitalisasi sehingga biaya yang dikeluarkan untuk berobat otomatis meningkat (Ma et al., 2019), sehingga diperlukan suatu sistem yang dapat diaplikasikan dari rmah dan dapat diakses oleh tenaga kesehatan. Studi telaah jurnal ini dilakukan untuk memberikan gambaran tentang keefektifan pengembangan dan penerapan Rekam Medis Elektronik untuk memantau insiden Hipertensi.

\section{METODE}

Metode yang diterapkan untuk penelitian ini adalah telaah jurnal. Telaah jurnal adalah suatu studi yang 
dilakukan untuk menganalisa literatur literatur yang dipilih dari berbagai sumber yang bertujuan menjadi sebuah gagasan baru. Jurnal yang digunakan dalam studi ini adalah jurnal jurnal yang membahas topik dengan kata kunci yaitu; Nursing Informatics, Electronic Health Record, Hypertension, Monitoring Hypertension, Monitoring Blood Pressure. Penelusuran jurnal ini melalui online database diantaranya: ScienceDirect, J-Stor, Clinical Key, dan ProQuest dari tahun 2016-2020.

\section{HASIL}

Dalam proses pemilihan jurnal, ada beberapa criteria inklusi yaitu: 1) full-text, 2) berbahasa Inggris, 3) Semua metoda penelitian 4) berkaitan dengan layanan kesehatan, 5)dipublikasikan antara tahun 2016-2020 dan 6) penelitian di luar negeri. Kriteria eksklusi adalah penelitian yang berupa telaah jurnal seperti scoping review dan sistematik/literature review. Setelah disesuaikan dengan criteria inklusi didapatkan 30 jurnal yang sesuai. Kemudian berdasarkan kesesuaian topik yang ingin dibahas ditetapkan 10 jurnal untuk dibahas lebih lanjut. Berikut merupakan jurnal-jurnal pilihan yang peneliti analisis dalam studi literature reviewini:

Tabel 1. Rincian Hasil Jurnal Pilihan Utama untuk Literature Review

\begin{tabular}{ccccccc}
\hline $\begin{array}{c}\text { No } \\
\text { Penulis/ } \\
\text { Tahun }\end{array}$ & $\begin{array}{c}\text { Judul } \\
\text { Penelitian }\end{array}$ & $\begin{array}{c}\text { Nama } \\
\text { Jurnal }\end{array}$ & $\begin{array}{c}\text { Tujuan } \\
\text { Penelitian }\end{array}$ & $\begin{array}{c}\text { MetodePene } \\
\text { litian }\end{array}$ & Hasil Penelitian \\
\hline 1 & Chatrati, Smart home health & Journal of & Mengidentifikasi & Studi & jgunaan & sIstem
\end{tabular}

S.P, et al monitoring system for King Saudy keefektifan penggunaan experimental monitoring kesehatan di

(2020) predicting type 2 University system monitoring diabetes kesehatan di rumah untuk andHypertension menganalisa adanya nilai tekanan darah dan gula darah yang abnormal

2 Chen, Identifying Elsevier

$\mathrm{Lu}$, et al hypertension in

(2020) pregnancy using electronic medical records:

Theimportance of blood pressure values

3 Gini. R, Automatic

et al identification of type

(2016) 2diabetes,

hypertension,

ischaemic

heartdisease, heart

failure and their

levelsof severity from

Italian

GeneralPractitioners'

electronic medical

records: a validation

study

4 Su, J., et Developing a

al cardiovaskular

(2017) disease risk factor

annonated corpus of

Chinese electronic

\section{$B M C$}

Medical

Informatics

and

BMJ Open

Mengidentifikasi
hipertensi
kehamilan

kehamilan

yang terintegrasi antara

pencatatan tekanan

darah, diagnosa penyakit

dan pengobatan anti

hipertensi

Decision risiko CVD yang berasal CEMR
Untukmengetahuivalidita Validation

s Health Search/CSD study

Longitudinal Patient

Database (HSD) yang

dapatmengidentifikasialg

oritmapenyakitsecaraoto

matis
StudiKohort sgunaan data EMR yang

terintegrasi antara

pencatatan tekanan

darah, diagnose

penyakit dan riwayat

pengobatan anti

hipertensi dapat

mengidentifikasi secara

dini adanya hipertensi selama kehamilan.

1 penelitian menunjukan bahwa otomatisasi

identifikasi algoritma

yang berasal dari Health

Search/CSD

,itudinal Patient

Database (HSD) secara valid dapat menunjukan individu/pasien dengan DM Type 2, Hipertensi, Penyakit Jantung Iskemik dan Gagal Jantung

Untuk mengumpulkan Studideskript sgunaan annotations annotations dari factor if pada Chinese electronic medical Record

berperan secara

signifikan dalam 
Medical Record Making

(CEMR)

5 Ma, Y The effectiveness of Internation Untuk mengidentifikasi Systematic

(2018) electronic helath

al Journal keefektifan penggunaan Review and interventions on blood Of Nursing e-health pressure control, self Studies carebehavioral

outcomes and psychosocial well being in patients hypertension: A systematic review and meta-analysis

6 Grove, Using electronic D.H et clinical quality

Morbidity and al measure reporting for (2015)

mengontrol darah, perubahan perilaku yang berkaitan dengan selfcare dan psikososial yang adekuat

Untuk mengidentifikasi Studi dan menganalisa deskriptif penggunaan electronical clinical quality measure mortality weekly report dalam program surveilans kesehatan komunitas

J Gen

Untuk menguji hubungan Studi ty, M Discharge Blood \&Sahni, Pressure $\mathrm{N} \quad$ with Post-discharge

(2019) Outcomes Using Electronic Medical Record Data: a Retrospective Study

8 Lê- Identifying Scherba neighborhood $\mathrm{n}$, F. et characteristics al associated with (2019) diabetes and hypertension control in an urban AfricanAmerican population using geolinked electronic health records

9 Ozer, Effects of electronic

$\mathrm{O} \&$ medical records on $\mathrm{F}$ Santas, patient safety

(2019) culture:The perspective of nurses
Intern Med antara tekanan darah Retrospektif sistolik selama di hospitalisasi dengan tekanan darah sistolik 30 hari setelah perawatan dengan menggunakan Electronic medical record

Preventive Penggunaangeo-linked Cross medicine electronic health untuk sectional report mengetahui adanya study hubungan antara karakteristik lingkungan perumahan Amerika Afrika dengan kasus hipertensi-diabetes

Journal Of Untuk menginvestigasi Evaluation dari sudut pandang

In Clinical perawat pengaruh Practice penggunaan rekam medis elekronik dengan budaya keselamatan pasien multiple mengelola factor factor risiko dari CVD sgunaan e-health memberikan pengaruh positif dalam pengontrolan tekanan darah dan menjadi alternative yang menjanjikan dalam tata laksana hipertensi

1 analisa menggambarkan bahwa penggunaan electronical clinical quality measure dapat menjadi instrument untuk memonitoring kondisi kesehatan secara populasi/ komunitas nya hubungan secara signifikan antara tekanan darah sistolik selama di hospitalisasi dengan kenaikan tekanan darah sistolik 30 hari setelah perawatan.

is hipertensi dan DM yang tidak terkontrol terjadi pada lingkungan yang terpencil dan jarang dilewati oleh umum. Hal ini berkaitan dengan ketimpangan social ekonomi, tingginya angka kejahatan, pendapatan yang minim serta perawatan medis yang kurang tepat

$\begin{array}{ll}\text { Studi } & \text { Hasil penelitian } \\ \text { korelasi dan } & \text { menjelaskan bahwa ada }\end{array}$ regresi korelasi secara signifikan persepsi perawat tentang penggunaan rekam medis elektronik yang berpengaruh terhadap budaya keselamatan pasien secara positif. 


\begin{tabular}{|c|c|c|c|c|c|}
\hline 10 & $\begin{array}{l}\text { Corey, } \\
\text { K.E et } \\
\text { al } \\
\text { (2016) }\end{array}$ & $\begin{array}{lr}\text { Using an } & \text { Electronic } \\
\text { Medical } & \text { Records } \\
\text { Database to } & \\
\begin{array}{l}\text { Identify } \\
\text { Traditional }\end{array} & \\
\text { Cardiovascular } & \text { Risk } \\
\text { Factors } & \\
\text { inNonalcoholic } & \text { Fatty } \\
\text { Liver Disease } & \end{array}$ & $\begin{array}{l}\text { American } \\
\text { Journal of } \\
\text { Gastroent } \\
\text { erology }\end{array}$ & $\begin{array}{l}\text { Untuk mengidentifikasi Studi Cohort } \\
\text { factor risiko penyebab } \\
\text { penyakit } \\
\text { cardiovascular: umur, } \\
\text { jenis kelamin, } \\
\text { kolesterol, level HDL, } \\
\text { status merokok, dan } \\
\text { hipertensi pada } \\
\text { penyakit liver non } \\
\text { alkoholik berdasarkan } \\
\text { data dari rekam medis } \\
\text { elektronik }\end{array}$ & $\begin{array}{l}\text { Hasil studi menjelaskan } \\
\text { bahwa factor risiko } \\
\text { seperti usia, riwayat } \\
\text { keluarga, hipertensi dan } \\
\text { gagal ginjal dapat } \\
\text { mencetuskan penyakit } \\
\text { cardiovascular pada } \\
\text { pasien dengan penyakit } \\
\text { liver non alkoholik. }\end{array}$ \\
\hline
\end{tabular}

\section{PEMBAHASAN}

Hasil dari sepuluh telaah literatur didapatkan bahwa semua jurnal membahas pengembangan dan penerapan RME dalam memantau insiden hipertensi. Menurut penelitian, penggunaan RME yang bertujuan untuk mengidentifikasi keefektifan penggunaan RME dalam mengontrol tekanan darah, perubahan perilaku, yang berkaitan dengan self care, dan psikososial yang adekuat ternyata dapat memberikan pengaruh yang positif dalam pengontrolan tekanan darah (Ma et al, 2019). Pemanfaatan penggunaan RME sudah berkembang luas untuk mendeteksi suatu penyakit atau memonitoring penyakit tertentu serta mencegah rehospitalisasi. Penggunaan RME bisa menjadi alternatif dalam tatalaksana intervensi hipertensi.

Kasus hipertensi rentan terhadap kejadian rehospitalisasi. Kejadian rehospitalisasi dapat terjadi setelah satu bulan paska rawat inap di RS. Menurut Khambaty (2019), kejadian tekanan darah sistolik setelah 30 hari perawatan mengalami kenaikan secara signifikan dibanding tekanan darah sistolik selama hospitalisasi. Kejadian rehospitalisasi terjadi karena pasien tidak mengontrol penyakitnya. Pada penelitian yang dilakukan oleh Scherban (2019), kasus hipertensi yang tidak terkontrol sering terjadi pada lingkungan yang terpencil. Hal ini berkaitan dengan ketimpangan sosial ekonomi, tingginya angka kejahatan, pendapatan minim serta perawatan kesehatan yang kurang tepat.

Pemanfaatan RME juga bisa mendeteksi adanya factor pencetus penyakit lain seperti penyakit kardiovaskular dengan mengidentifikasi factor risiko salah satunya adalah Hipertensi. Menurut Corey (2016), pada pasien penyakit liver nonalkoholik yang mencetuskan penyakit kardiovaskular disebabkan adanya factor risiko seperti riwayat hipertensi dan gagal ginjal. Riwayat keluarga dengan penyakit kardiovaskular dapat mencetuskan pasien untuk mengalami penyakit kardiovaskular. Pada penelitian lain, identifikasi secara dini adanya hipertensi selama kehamilan atau pre-eklamsi bisa diketahui dari awal melalui penggunaan data RME yang terintegrasi dengan adanya pencatatan tekanan darah, diagnosa penyakit dan riwayat pengobatan sebelumnya (Chen et al, 2020). Menurut Chen (2020), hipertensi selama kehamilan yang diketahui secara dini dapat memberikan kesempatan tenaga kesehatan memberikan intervensi dan terapi dengan tepat, sehingga hal-hal yang dapat memperburuk kondisi pasien dapat dicegah.

Pemanfaatan RME dengan menggunakan fitur canggih seperti algoritma yang otomatis menegakkan diagnosis, anotasi ataupun monitoring yang terhubung dengan tempat tinggal pasien sudah diuji di beberapa jurnal. Penelitian Chatrati (2020) menyebutkan penggunaan system monitoring kesehatan di rumah berkontribusi secara signifikan dalam menganalisa hasil dari tekanan darah dan gula darah sehingga secara otomatis mendeteksi status penyakit pasien berdasarkan algoritma yang sudah di setting di system tersebut. Penggunaan algoritma secara otomatis di system RME yang berfungsi untuk mengidentifikasi penyakit DM, hipertensi, penyakit jantung iskemik dan gagal jantung pun sudah digunakan di Rumah Sakit yang berada di Italia dan terbukti sudah valid berdasarkan penelitian yang dilakukan oleh Gini (2016). Selain algoritma yang sudah banyak aplikasikan dalam RME, penggunaan anotasi seharusnya sudah mulai dipertimbangkan. Penggunaan anotasi dalam system RME di China, membantu tenaga medis dalam mengelola factor factor risiko dari penyakit cardiovaskuler. Semakin banyak anotasi yang terkumpul, semakin banyak data yang bisa diidentifikasi sebagai factor risiko penyakit cardiovascular (Su et al., 2017). Sehingga penggunaan RME memberikan dampak positif dalam memonitoring dan mengidentifikasi penyakit pasien khususnya Hipertensi.

\section{KESIMPULAN}

Pemanfaatan RME bisa digunakan untuk memonitoring penyakit hipertensi atau mendeteksi suatu 
penyakit akibat hipertensi dan mencegah kejadian rehospitalisasi. Pemanfaatan RME sudah mulai dikembangkan secara luas, terbukti dengan adanya fitur algoritma yang secara otomatis mendeteksi penyakit, penggunaan anotasi serta monitoring yang terhubung dengan tempat tinggal pasien. Pengembangan dan pemanfaatan RME sangat berpotensi untuk mengontrol penyakit dan mendukung peningkatan kualitas kesehatan. Sistem RME perlu lebih dikembangkan lebih luas dan adanya inovasi terkait sistem RME yang mendukung perbaikan kesehatan baik dalam pelayanan kesehatan secara individu maupun komunitas.

\section{REFERENSI}

Chatrati, S. P., Hossain, G., Goyal, A., Bhan, A., Bhattacharya, S., Gaurav, D., \& Tiwari, S. M. (2020). 'Smart home health monitoring system for predicting type 2 diabetes and hypertension'. Journal of King Saud University - Computer and Information Sciences. Retrieved March 6, 2020. doi:10.1016/j.jksuci.2020.01.010

Chen, L., Shortreed, S. M., Easterling, T., Cheetham, T. C., Reynolds, K., Avalos, L. A., Kamineni, A., Holt, V., Neugebauer, R., Akosile, M., Nance, N., Bider-Canfield, Z., Walker, R. L., Badon, S. E., \& Dublin, S.(2020). 'Identifying hypertension in pregnancy using electronic medical records: The importance of blood pressure values'. Pregnancy Hypertension. Retrieved March 6, 2020. https://doi.org/10.1016/j.preghy.2020.01.001

Corey, K. E., Kartoun, U., Zheng, H., Chung, R. T., \& Shaw, S. Y. (2016). 'Using an electronic medical records database to identify non-traditional cardiovascular risk factors in nonalcoholic fatty liver disease'. The American Journal of Gastroenterology, 111(5), 671-676. Retrieved March 7, 2020. doi:http://dx.doi.org/10.1038/ajg.2016.44

Gini, R., Schuemie, M. J., Mazzaglia, G., Lapi, F., Francesconi, P., Pasqua, A., . . Klazinga, N. (2016). 'Automatic identification of type 2 diabetes, hypertension, ischaemic heart disease, heart failure and their levels of severity from italian general practitioners' electronic medical records: A validation study'. BMJ Open, 6(12). Retrieved March 7, 2020 doi:http://dx.doi.org/10.1136/bmjopen-2016-012413

Heisey-Grove, D., Wall, H., Helwig, A., \& Wright, J. (2015). 'Using Electronic Clinical Quality Measure Reporting for Public Health Surveillance'. Morbidity and Mortality Weekly Report, 64(16), 439-442. Retrieved March 27, 2020, from www.jstor.org/stable/24856471

Kementerian Kesehatan RI. (2020). 'Info datin; hipertensi'. Jakarta: Pusat Data dan Informasi Kementerian $\begin{array}{lllll}\text { Kesehatan } & \text { RI. } & \text { Maret } & 620 .\end{array}$ https://pusdatin.kemkes.go.id/resources/download/pusdatin/infodatin/infodatin-hipertensi.pdf

Khambaty, M \& Sahni, N. (2019). 'Association of final discharge blood pressure with post-discharge outcomes using electronic medical record data: a retrospective study'. Journal of General Internal Medicine, 34(8), 1373-1374. Retrieved March 7, 2020 https://doi.org/10.1007/s11606-019-04981-0

Lê-Scherban, F., Ballester, L., Castro, J. C., Cohen, S., Melly, S., Moore, K., \& Buehler, J. W. (2018;2019);. 'Identifying neighborhood characteristics associated with diabetes and hypertension control in an urban african-american population using geo-linked electronic health records'. Preventive Medicine Reports, 15, 100953-100953. Retrieved March 6, 2020. http://www.sciencedirect.com/science/article/pii/S2211335519301251

Ma, Y., Cheng, H. Y., Cheng, L., \& Sit, J. W. H. (2019). 'The effectiveness of electronic health interventions on blood pressure control, self-care behavioural outcomes and psychosocial well-being in patients with hypertension: A systematic review and meta-analysis'. In International Journal of Nursing Studies. Retrieved March 6, 2020. https://doi.org/10.1016/j.ijnurstu.2018.11.007

Özer, Ö., \& Şantaş, F. (2020). 'Effects of electronic medical records on patient safety culture: The perspective of nurses'. Journal of Evaluation in Clinical Practice, 26(1), 72-78. Retrieved March 6, 2020. https://doi.org/10.1111/jep.13174

Su, J., He, B., Guan, Y., Jiang, J., \& Yang, J. (2017). 'Developing a cardiovascular disease risk factor' annotated corpus of Chinese electronic medical records'. BMC Medical Informatics and Decision MakingRetrieved March 6, 2020. https://doi.org/10.1186/s12911-017-0512-7

Kemenkes RI. (2018). 'Laporan Nasional Riskesdas 2018'. Jakarta: Badan Penelitian dan Pengembangan $\begin{array}{lllll}\text { Kesehatan Kemenkes } & \text { RI. } & \text { Maret } & 620\end{array}$ http://kesmas.kemkes.go.id/assets/upload/dir 519d41d8cd98f00/files/Hasil-riskesdas-2018 1274.pdf 